\title{
Rhabdomyolysis Reported for Children and Adolescents Treated with Antipsychotic Medicines: A Case Series Analysis
}

\author{
Kristina Star, B.Sc., ${ }^{1,2}$ Noha lessa, M.Pharm., ${ }^{3}$ Noor B. Almandil, B.Sc. Pharm., M.Sc., ${ }^{3}$ \\ Lynda Wilton, Ph.D., ${ }^{3}$ Sarah Curran, M.B., B.Ch., B.A.O., Ph.D., M.R.C.P.C.H., M.R.C.Psych., \\ I. Ralph Edwards, M.B., Ch.B., M.R.C.S. (Lond.), F.R.C.P. (Lond.), F.R.A.C.P., F.R.C.P. (Edin.), \\ and lan C.K. Wong, B.Sc. Pharm., M.Sc., Ph.D., F.R.Pharm.S., F.R.C.P.C.H. (Hon.) $)^{3,5}$
}

\begin{abstract}
Objective: Rhabdomyolysis is a rare and potentially serious adverse drug reaction (ADR) to antipsychotic medicines. The aim of this study was to investigate the clinical circumstances surrounding the diagnosis of rhabdomyolysis in children and adolescents treated with antipsychotic medicines. We also critically reviewed individual case safety reports (ICSRs) of suspected ADRs to evaluate how clinically useful they can be in a case series analysis.

Methods: This was a descriptive and an exploratory study. Published case reports and ICSRs from the World Health Organization (WHO) Global ICSR database, VigiBase, reported with rhabdomyolysis and antipsychotic medicines for patients $\leq 17$ years years of age were described. Reporting patterns of ICSRs with rhabdomyolysis and antipsychotic medicines were explored in VigiBase for children and adolescents and for adults. The VigiBase ICSRs were also systematically evaluated regarding the report content.

Results: Of the 26 evaluated reports, 6 co-reported neuroleptic malignant syndrome (NMS) and 20 reports concerned rhabdomyolysis in the absence of NMS. The reported suspected antipsychotic medicines for these 20 reports were olanzapine, risperidone, haloperidol, paliperidone, quetiapine, clozapine, cyamemazine, and aripiprazole. In VigiBase, rhabdomyolysis (in the absence of NMS) was reported more frequently with olanzapine relative to all reports for children and adolescents with antipsychotic medicines. In the range of events that preceded rhabdomyolysis, muscle pains and abdominal pain were commonly recorded to have started during the week prior to the diagnosis. Other preceding symptoms were general weakness and dark urine. Onset of rhabdomyolysis for most patients occurred at any time within 2 months of starting antipsychotic treatment, in several cases triggered by changes to the patient's drug therapy or known risk factors of rhabdomyolysis. It was found that ICSRs can contribute with additional information, but that access to free text and narratives were crucial in order to capture clinically useful features of rhabdomyolysis.

Conclusion: Monitoring of children and adolescents needs to be intensified during dose increases, or when a new, added, or switched antipsychotic medicine is introduced to their drug regimen, and during exposure to known risk factors for rhabdomyolysis. The development of seemingly nonserious events, such as abdominal pain, muscle pain, weakness, and dark urine, should be followed up during antipsychotic use, as they might be precursory events to rhabdomyolysis that eventually could develop into acute renal failure.
\end{abstract}

\section{Introduction}

A NTIPSYCHOTIC MEDICINES, PARTICULARLY THE ATYPICAL, are increasingly being prescribed for children and adolescents (Olfson et al. 2006; Rani et al. 2008). These medicines are used for a range of psychiatric disorders such as schizophrenia, psychosis, bipolar disorders, attention-deficit/hyperactivity disorders (ADHD), autism, and conduct disorders (Cheng-Shannon et al. 2004), often outside licensed indications for younger age groups (Pathak et al. 2010; Almandil et al. 2011). The high incidence of adverse drug reactions (ADRs) induced by antipsychotics and the suggested higher susceptibility of children to certain ADRs makes

\footnotetext{
${ }^{1}$ Uppsala Monitoring Centre, WHO Collaborating Centre for International Drug Monitoring, Uppsala, Sweden.

${ }^{2}$ Department of Public Health and Caring Sciences, Uppsala University, Uppsala, Sweden.

${ }^{3}$ Centre for Paediatric Pharmacy Research, School of Pharmacy, University College London, United Kingdom.

${ }^{4}$ Academic Department of Child \& Adolescent Psychiatry, Institute of Psychiatry, King's College London, United Kingdom.

${ }^{5}$ Department of Pharmacology and Pharmacy, Li Ka Shing Faculty of Medicine, The University of Hong Kong, Hong Kong.
} 
this continuous increase in use a concern (Correll et al. 2006; Jerrell et al. 2008; Rani et al. 2009). Problematic and common ADRs seen in the pediatric population with antipsychotic therapy are: weight gain (Almandil et al. 2012); lipid and liver transaminase alterations, particularly for olanzapine; more elevated prolactin levels for risperidone; and more severe extrapyramidal symptoms for haloperidol (Sikich et al. 2004, 2008).

A rarer and potentially serious but less documented ADR from antipsychotic medicines is rhabdomyolysis presenting in the absence of neuroleptic malignant syndrome (NMS). Rhabdomyolysis is caused by skeletal muscle destruction resulting in leakage of muscle constituents into plasma. Clinical features of the syndrome are myalgia, weakness, dark urine, elevated serum creatine phosphokinase (CPK), and myoglobinuria, possibly leading to acute renal failure and compartment syndrome (Gabow et al. 1982; Elsayed et al. 2010). Common causes for rhabdomyolysis are, specifically in children, viral myositis (Mannix et al. 2006; Wu et al. 2009), and in adolescents, trauma and drug overdose/reaction (Mannix et al. 2006). Illicit drugs/ alcohol, prescribed drugs, muscle diseases, trauma and NMS, were the most common causes of rhabdomyolysis observed in a study on 475 hospitalized child and adult patients. Eleven percent of the rhabdomyolysis cases (in the absence of NMS) were caused by "prescribed drugs," of which haloperidol, atypical antipsychotics, and phenothiazines were the most frequently represented drugs (Melli et al. 2005).

Antipsychotic-induced rhabdomyolysis, in the absence of NMS, has been highlighted in a limited number of published case reports on children and adolescents (Yoshikawa et al. 2000; Rosebraugh et al. 2001; Holtmann et al. 2003; Strawn et al. 2008; Hung et al. 2009; Karakaya et al. 2010). Detailed published case reports are a valuable source of information to increase our understanding of a clinical problem (Vandenbroucke 1999, 2001). These important case histories can sometimes be our only data source on rare and serious ADRs occurring in small subpopulations, such as children. A potential additional source could be international pharmacovigilance reports collected during postmarketing drug use. In the current study, we reviewed published case reports and pharmacovigilance reports to investigate the clinical circumstances surrounding the diagnosis of rhabdomyolysis in children and adolescents taking antipsychotic medicines. We also critically reviewed the use of pharmacovigilance reports in a clinical case series analysis.

\section{Methods}

This was a descriptive and exploratory study using reports of rhabdomyolysis occurring during treatment with antipsychotic medicines in children and adolescents. The reports consisted of published case reports and individual case safety reports (ICSRs) from the World Health Organization (WHO) Global ICSR database, VigiBase, maintained by Uppsala Monitoring Centre, the WHO Collaborating Centre for International Drug Monitoring (Lindquist 2008). Three analyses were conducted:

1. An overview of disproportionate reporting patterns in VigiBase of ICSRs for children and adolescents and for adults.

2. A case series analysis of published case reports and VigiBase ICSRs, following detailed review of each case, which included causality assessment of each report.

3. A critical review of the VigiBase ICSRs to determine their clinical usefulness in a case series analysis.

\section{VigiBase Dataset and Terminologies}

Antipsychotic medicines in this study were classified according to the WHO Anatomical Therapeutic Chemical (ATC) classification group, N05A (WHO Collaborating Centre for Drug Statistics Methodology 2009). VigiBase ICSRs coded with the Medical Dictionary for Regulatory Activities (MedDRA) Preferred Term (PT) rhabdomyolysis were retrieved (Maintenance and Support Service Organization [MSSO] 2010). The focus of this article was on rhabdomyolysis in the absence of NMS, therefore the reports were separated in two groups:

- ICSRs with the MedDRA PT rhabdomyolysis reported without neuroleptic malignant syndrome, referred to as the "RM group."

- ICSRs with the MedDRA PT rhabdomyolysis co-reported with neuroleptic malignant syndrome, referred to as the "RM+ NMS group."

For the ICSRs for $\leq 17$ years of age, the complete ICSRs were manually reviewed to confirm classification of the ICSR to the "RM group" and the "RM + NMS group."

The dataset used in this study includes ICSRs entered in VigiBase up to February 5, 2010. At the time of the study, 97 countries had contributed almost 5,000,000 ICSRs to VigiBase. The reports are collected following marketing of a medicinal product, primarily to detect safety problems that were not identified in premarketing clinical studies. In the initial extraction of reports, an automated screening of duplicates was applied (Norén et al. 2007). Duplication of reports can occur in large compilations of data when reports of the same event are sent from more than one source.

\section{Disproportionate Reporting Patterns in VigiBase}

This quantitative evaluation was restricted to data available as structured information in the VigiBase dataset. Associations between drugs and ADRs were identified using the Information Component (IC). The IC is a measure of disproportionality, computed as the logarithm of a shrinkage observed-to-expected ratio (Bate et al. 1998; Norén et al. 2011). A positive IC value indicates that a particular drug-ADR pair is reported more often than expected, based on all reports in the subgroups used in this study. The IC 025 value is the lower limit of a $95 \%$ credibility interval of the IC and provides information about the robustness of a specific IC value. The IC does not imply causality of a potential ADR and a drug, but is used to highlight disproportionate reporting patterns for further evaluation, using IC025 >0 as the threshold.

To explore the overall reporting pattern of ICSRs for children and adolescents (2-17 years) and for adults ( $\geq 18$ years), the observed-to-expected ratio was calculated for reports with antipsychotic medicines and rhabdomyolysis co-reported with and without NMS for each age group. The computed expected value was based on the overall reporting of rhabdomyolysis with and without NMS with any drug in each age group.

The reporting frequency for the three most commonly reported suspected antipsychotic drug substances with rhabdomyolysis among children and adolescents in VigiBase was explored. The relative reporting frequency was calculated for ICSRs with rhabdomyolysis, coreported with and without NMS, and each of the antipsychotic drug substances relative to the overall reporting of the drug for children and adolescents ( $2-17$ years) and for adults ( $\geq 18$ years). The lower limit of the $95 \%$ credibility interval of the shrinkage observed-to-expected ratio (Norén et al. 2011) was used to highlight disproportionate reporting of rhabdomyolysis with or without NMS with each of the 
suspected antipsychotic drug substances relative to the overall reporting of the defined terms with antipsychotic medicines in the age group.

\section{Detailed Case Series Analysis of VigiBase Original Reports and Published Case Reports}

For the detailed case series analysis, a systematic review of the VigiBase ICSRs and the published case reports was performed and a causality assessment of each report was conducted. For this analysis, VigiBase original reports were used. If the VigiBase ICSR existed also as a published case report, the published report was used in the review. The data elements recommended to be considered when describing features of an adverse event report was used as a guideline in the case series analysis (Kelly et al. 2007).

\section{VigiBase individual case safety reports}

Reports with the MedDRA PT rhabdomyolysis and an antipsychotic medicine concerning patients $\leq 17$ years of age were retrieved as previously described. The anonymous original VigiBase case report files were requested and received from the national pharmacovigilance centers contributing the reports, and were used in the detailed case series analysis. A manual screening of suspected duplicate reports was performed.

\section{Published case reports}

Case reports were screened in the literature to increase the number of cases for review. In order to identify case reports we searched multiple databases including: EMBASE (1980-2010 week 21), PubMed (1969-2010), BIOSIS (1969-2009 week 27), and International Pharmaceutical Abstracts (1970 to May 2010) using the search terms in Table 1. In addition, the reference sections of all retrieved articles were manually searched for further relevant publications. We included case reports of rhabdomyolysis in the absence of NMS in children and adolescents 2-17 years of age treated with antipsychotic drugs. We included all cases with serious outcomes (as defined by the WHO as hospitalization and death) reporting the use of antipsychotics.

\section{Causality assessment}

Each VigiBase ICSR with rhabdomyolysis, co-reported with and without NMS, and published case report within our case series analysis was assessed for causality between the antipsychotic medicine and rhabdomyolysis by an expert assessment panel consisting of a clinical psychiatrist (SC), a pharmacoepidemiologist (LW) and a clinical pharmacist (NI). The panelists reviewed each case individually, using as tools the French imputability (Bégaud et al. 1985), Naranjo (Naranjo et al. 1981), and Jones algorithms (Jones 1982) as well as their expertise, to make a final assignment of causality according to the WHO definitions (Appendix A). Their final causality assignments, which were anonymous, were screened for disagreements by a separate investigator (NA). Any disagreements between assessors were fed back to the panelist, who had the possibility to revise their judgments. The final causality assignment for each case was made by consensus following discussion by the expert panel.

Table 1. Search Terms for Published Case Reports Concerning Children and Adolescents Reported With Antipsychotic Medicines and Rhabdomyolysis

\begin{tabular}{|c|c|c|c|c|c|c|}
\hline Subjects & & Drug & & Study design & & Adverse event \\
\hline $\begin{array}{l}\text { Children } \\
\text { or } \\
\text { Child } \\
\text { or } \\
\text { Paediatric } \\
\text { or } \\
\text { Pediatric } \\
\text { or } \\
\text { Juvenile } \\
\text { or } \\
\text { School child } \\
\text { or } \\
\text { Youth } \\
\text { or } \\
\text { Young } \\
\text { or } \\
\text { Adolescents } \\
\text { or } \\
\text { Adolescence } \\
\text { or } \\
\text { Teenage }\end{array}$ & AND & $\begin{array}{l}\text { Atypical antipsychotic drugs } \\
\text { or } \\
\text { New neuroleptic } \\
\text { or } \\
\text { Antipsychotic drugs } \\
\text { or } \\
\text { Second generation } \\
\text { Antipsychotics } \\
\text { or } \\
\text { Antipsychotics } \\
\text { or } \\
\text { Risperidone } \\
\text { or } \\
\text { Clozapine } \\
\text { or } \\
\text { Olanzapine } \\
\text { or } \\
\text { Aripiprazole } \\
\text { or } \\
\text { Quetiapine } \\
\text { or } \\
\text { Sertindole } \\
\text { or } \\
\text { Zotepine } \\
\text { or } \\
\text { Amisulpride } \\
\text { or } \\
\text { Haloperidol } \\
\text { or } \\
\text { Chlorpromazine }\end{array}$ & AND & $\begin{array}{l}\text { Case } \\
\text { or } \\
\text { Report } \\
\text { or } \\
\text { Case report } \\
\text { or } \\
\text { Case reports }\end{array}$ & AND & Rhabdomyolysis \\
\hline
\end{tabular}


Table 2. Number and Type of Reports Included in Each Part of the Analysis of Rhabdomyolysis Co-Reported With and Without Neuroleptic Malignant Syndrome (NMS) for Children and Adolescents Taking Antipsychotic Medicines, by VigiBase Individual Case Safety Reports (ICSRs) and Published Case Reports

\begin{tabular}{|c|c|c|c|c|}
\hline Part of analysis & $\begin{array}{l}\text { Total no. } \\
\text { reports }\end{array}$ & $\begin{array}{l}\text { VigiBase and/or } \\
\text { published reports }\end{array}$ & $\begin{array}{l}\text { No. reports: } \\
\text { rhabdomyolysis }\end{array}$ & $\begin{array}{c}\text { No. reports: } \\
\text { rhabdomyolysis } \\
\text { co-reported with NMS }\end{array}$ \\
\hline \multirow[t]{2}{*}{ Disproportionate reporting pattern } & \multirow[t]{2}{*}{22} & VigiBase ICSRs & 14 & 4 \\
\hline & & VigiBase ICSRs also published & $2^{\mathrm{a}}$ & $2^{\mathrm{c}}$ \\
\hline \multirow[t]{3}{*}{ Detailed case series analysis } & \multirow[t]{3}{*}{26} & VigiBase ICSRs & 14 & 4 \\
\hline & & VigiBase ICSRs also published & $2^{\mathrm{a}}$ & $2^{\mathrm{c}}$ \\
\hline & & Published reports (not included in VigiBase) & $4^{\mathrm{b}}$ & - \\
\hline Critical review of VigiBase ICSRs & 18 & VigiBase ICSRs & 14 & 4 \\
\hline
\end{tabular}

${ }^{a}$ Rosebraugh et al. 2001; Strawn et al. 2008, included in VigiBase dataset.

${ }^{b}$ Yoshikawa et al. 2000; Holtmann et al. 2003; Hung et al. 2009; Karakaya et al. 2010, not included in VigiBase dataset.

${ }^{c}$ Hanft et al. 2004; Watson et al. 2004, included in VigiBase dataset, not retrieved from literature search.

\section{Critical Review of Individual Case Safety Reports in VigiBase}

For this evaluation, the VigiBase ICSRs with rhabdomyolysis coreported with and without NMS and their corresponding original reports were used, excluding any reports also found in the literature. The following five areas were considered as particularly useful clinical information in the context of our study: Circumstances preceding the reaction; underlying risk factors; physical examination and laboratory test results; drug reaction time-to-onset; and treatment of the reaction. The report content was assessed in detail, investigating whether and where on the report the information was recorded.

\section{Results}

A total of 26 reports on children and adolescents were evaluated in this study, of which 20 were recorded with rhabdomyolysis in the abscence of NMS. Six published case reports (Yoshikawa et al. 2000; Rosebraugh et al. 2001; Holtmann et al. 2003; Strawn et al. 2008; Hung et al. 2009; Karakaya et al. 2010) and 22 individual VigiBase ICSRs were retrieved, of which two overlapped with reports retrieved from the literature (Rosebraugh et al. 2001; Strawn et al. 2008).

Twenty reports with rhabdomyolysis were judged not to concern NMS (RM group). The six VigiBase ICSRs that co-reported NMS $(\mathrm{RM}+\mathrm{NMS}$ group) are accounted for separately in this article. The analysis is in three parts and Table 2 displays the number and type of the 26 reports that are included in each:

1. The 22 VigiBase ICSRs were included in the disproportionate reporting pattern analysis.
2. All 26 reports were included in the detailed case series analysis, encompassing both the VigiBase ICSRs and published case reports.

3. Eighteen VigiBase ICSRs were included in the critical review of ICSRs, excluding the two overlapping published case reports in the RM group as well as two ICSRs in the $\mathrm{RM}+\mathrm{NMS}$ group that originated from the literature (Hanft et al. 2004; Watson et al. 2004).

\section{Disproportionate Reporting Patterns in VigiBase}

Rhabdomyolysis, with and without co-reported NMS, was disproportionally more frequently reported for antipsychotics than the overall reporting in each age group (Table 3 ). The lower limit of the 95\% credibility interval of the observed-to-expected ratio (IC025) for rhabdomyolysis reported without NMS for the child/adolescent age group was higher than the corresponding value for the adult group. In a subanalysis, lipid modifying agents were excluded (mostly used by adults and commonly reported with rhabdomyolysis) resulting in an increase of the IC025 for the adults from IC025: 0.39 to IC025: 1.90, whereas the corresponding values for the child/adolescent age group remained similar (changed from IC025: 0.78 to IC025: 0.81).

Table 4 displays the relative reporting frequency of ICSRs for rhabdomyolysis, co-reported with and without NMS, and any antipsychotic substance, olanzapine, risperidone, and haloperidol relative to the overall reporting of the drug group/drug for the children/adolescents and for the adults. Rhabdomyolysis reported without NMS was disproportionally more frequently reported for

Table 3. Observed-to-Expected Ratios, Presented with the Information Component (IC) for the Reporting of Antipsychotic Medicines and Rhabdomyolysis With and Without Neuroleptic Malignant Syndrome (NMS) by Age Group (VigiBase Data up to February 2010)

\begin{tabular}{llcrrr}
\hline Age group (years) & \multicolumn{1}{c}{ Defined ADR } & $\begin{array}{c}\text { Observed } \\
\text { no. reports }\end{array}$ & $\begin{array}{c}\text { Calculated expected } \\
\text { no. reports }\end{array}$ & IC & IC025 \\
\hline 2 to 17 & Rhabdomyolysis not NMS & 16 & 5.1 & 1.57 & 0.78 \\
& Rhabdomyolysis co-reported with NMS & 6 & 0.2 & 3.29 & 1.91 \\
& Rhabdomyolysis not NMS & 566 & 397.1 & 0.51 \\
& Rhabdomyolysis co-reported with NMS & 149 & 7.7 & 4.19 \\
\hline
\end{tabular}

${ }^{\text {a }}$ The lower limit of the $95 \%$ credibility interval of the shrinkage observed-to-expected ratio (IC025) $>0$ indicates disproportional reporting relative to the background of all reports with any drug in the age group.

$\mathrm{ADR}$, adverse drug reaction. 
Table 4. Number and Percentage of the Three Most Frequently Reported Antipsychotic Drug Substances Among Individual Case Safety Reports (ICSRs) for Children and Adolescents with Rhabdomyolysis Co-Reported With and Without Neuroleptic Malignant Syndrome (NMS) and Antipsychotic Drugs, Presented by Age Group (VigiBase Data up to February 2010)

\begin{tabular}{llcccc}
\hline $\begin{array}{c}\text { Age group } \\
\text { (years) }\end{array}$ & \multicolumn{1}{c}{ Defined ADR } & $\begin{array}{c}\text { Any antipsychotic drug } \\
\text { no. reports (\%) }\end{array}$ & $\begin{array}{c}\text { Olanzapine } \\
\text { no. reports (\%) }\end{array}$ & $\begin{array}{c}\text { Risperidone } \\
\text { no. reports (\%) }\end{array}$ & $\begin{array}{c}\text { Haloperidol } \\
\text { no.reports (\%) }\end{array}$ \\
\hline 2 to 17 & Rhabdomyolysis not NMS & $16(0.18)$ & $9(0.90)^{\mathrm{a}}$ & $4(0.20)$ & $2(0.29)$ \\
& Rhabdomyolysis co-reported with NMS & $6(0.07)$ & $2(0.20)$ & $1(0.05)$ & $2(0.29)$ \\
& Any ADR (total drug) & 9095 & 1003 & 2014 & 680 \\
$\geq 18$ & Rhabdomyolysis not NMS & $566(0.38)$ & $141(0.80)^{\mathrm{a}}$ & $97(0.55)^{\mathrm{a}}$ & $49(0.46)$ \\
& Rhabdomyolysis co-reported with NMS & $149(0.10)$ & $40(0.23)^{\mathrm{a}}$ & $18(0.10)$ & $29(0.27)^{\mathrm{a}}$ \\
& Any ADR (total drug) & 149,580 & 17,700 & 17,717 & 10,591 \\
\hline
\end{tabular}

Percentage $=$ number of reports for each defined ADR and drug/total number of reports for the drug in age group.

${ }^{\text {a }}$ The lower limit of the $95 \%$ credibility interval of the shrinkage observed-to-expected ratio is $>0$, indicating disproportional reporting relative to the background of all reports of antipsychotic drug substances with the defined ADR in the age group.

ADR, adverse drug reaction.

olanzapine $(0.90 \%)$ relative to the overall reporting of the defined term with antipsychotic medicines for children and adolescents $(0.18 \%)$.

\section{Detailed Case Series Analysis of VigiBase Individual Case Safety Reports and Published Case Reports}

\section{Patient demographics}

The 26 VigiBase ICSRs and published case reports originated from eight countries, of which 15 reports came from the United States. Patient demographics are summarized for reports with known values and displayed in Table 5, with the total 26 patients as one group and also rhabdomyolysis with and without co-reported NMS separately.

Weight (but not height) was recorded for 9 patients. One 17year-old male (RM + NMS) presented as being overweight and a second 16-year-old male (RM group) appeared to be overweight but its presentation was less obvious.

\section{Suspected medicines}

For 14 of the 20 cases in the RM group, the antipsychotic medicine(s) was reported as the only suspected drug(s) for rhabdomyolysis. In six reports, additional drugs other than antipsy- chotic medicines were co-suspected. For the RM+NMS group, three of the six reports included an antipsychotic medicine as a single suspected drug. The suspected drugs are displayed in Table 6 .

\section{Causality assessment}

The 26 reports were assessed for causality by an expert panel. In the final consensus round, there was a full agreement of which WHO causality criteria to assign to each individual case. See Table 7 with the distribution of cases for each causality criterion used.

\section{Clinical features}

In the RM group, signs and symptoms preceding rhabdomyolysis as well as those presented on the day of diagnosis were specified in 17 reports (Table 8). Twelve cases had aches and pain, of which abdominal pain/cramps and general muscle pain were the most common.

\section{Laboratory parameters}

The creatine kinase (CPK/CK) values were specified in 15/20 reports in the RM group and the peak CPK/CK ranged from 858 to $95,000 \mathrm{U} / \mathrm{L}$. In the RM+NMS group, values for 5/6 reports were

Table 5. Patient Demographics for the 26 Children and Adolescents Reported with Antipsychotic Medicines and Rhabdomyolysis With and Without Neuroleptic Malignant Syndrome (NMS)

\begin{tabular}{|c|c|c|c|}
\hline & All reports in case series & Rhabdomyolysis & $\begin{array}{c}\text { Rhabdomyolysis } \\
\text { co-reported with NMS }\end{array}$ \\
\hline No. reports & 26 & 20 & 6 \\
\hline Median age (range) & 14.5 (5 to 17$)$ & 14.5 (6 to 17$)$ & $14.5(5$ to 17$)$ \\
\hline Males & $21(81 \%)$ & $16(80 \%)$ & $5(83 \%)$ \\
\hline $\begin{array}{l}\text { Ethnic origin } \\
\quad \text { (specified in } 8 \text { reports) }\end{array}$ & $\begin{array}{l}\text { Caucasian }(n=4) \text {, } \\
\text { African American }(n=3) \text {, } \\
\text { Asian }(n=1)\end{array}$ & $\begin{array}{l}\text { Caucasian }(n=4), \\
\text { African American }(n=2), \\
\text { Asian }(n=1)\end{array}$ & $\begin{array}{l}\text { African American } \\
\quad(n=1)\end{array}$ \\
\hline $\begin{array}{l}\text { Most frequently reported } \\
\text { indications (indication } \\
\text { was specified in a total } \\
\text { of } 22 \text { reports) }\end{array}$ & $\begin{array}{l}\text { Schizophrenia }(n=6), \\
\text { bipolar disorder }(n=5), \\
\text { psychosis }(n=4) \text {, obsessive } \\
\text { compulsive disorder }(n=3), \\
\text { aggression }(n=2), \operatorname{ADHD}(n=2)\end{array}$ & $\begin{array}{l}\text { Bipolar disorder }(n=5), \\
\text { schizophrenia }(n=4), \\
\text { obsessive compulsive } \\
\text { disorder }(n=3), \text { psychosis }(n=2), \\
\text { aggression }(n=2) \text {, ADHD }(n=2)\end{array}$ & $\begin{array}{l}\text { Schizophrenia }(n=2), \\
\text { psychosis }(n=2)\end{array}$ \\
\hline
\end{tabular}

${ }^{a}$ One report can contain more than one stated indication.

ADHD, attention deficit hyperactivity disorder. 
Table 6. Suspected Drug Substances for the 26 Children and Adolescents Reported with Antipsychotic Medicines and Rhabdomyolysis With and Without Neuroleptic Malignant Syndrome (NMS)

\begin{tabular}{|c|c|c|}
\hline & Rhabdomyolysis & $\begin{array}{l}\text { Rhabdomyolysis co-reported } \\
\text { with NMS }\end{array}$ \\
\hline $\begin{array}{l}\text { Single and co-suspected } \\
\text { antipsychotic medicine(s) }\end{array}$ & $\begin{array}{l}\text { Olanzapine }(n=6) ; \text { risperidone }(n=3) \\
\text { haloperidol }(n=1) ; \text { paliperidone }(n=1) ; \\
\text { quetiapine }(n=1) \text {; risperidone }+ \text { haloperidol } \\
(n=1) ; \text { risperidone + olanzapine }(n=1)\end{array}$ & $\begin{array}{l}\text { Cyamemazine }(n=1) \text {; olanzapine }(n=1) \text {; } \\
\quad \text { ziprasidone }(n=1)\end{array}$ \\
\hline $\begin{array}{l}\text { Co-suspected medicines other } \\
\text { than antipsychotics }\end{array}$ & $\begin{array}{l}\text { Fluvoxamine + olanzapine }(n=1) \\
\text { olanzapine + lithium }(n=1)^{\mathrm{a}} \\
\text { olanzapine + topiramate }(n=1)^{\mathrm{b}} \\
\text { clozapine + benzatropine }(n=1) \\
\text { olanzapine + cyamemazine + valproate } \\
\text { sodium + haloperidol }(n=1) \\
\text { aripiprazole + venlafaxine + risperidone + } \\
\text { topiramate + zonisamide }(n=1)\end{array}$ & $\begin{array}{l}\text { Haloperidol }+ \text { trihexyphenidyl }+ \\
\text { tetrabenazine }(n=1) \text {; olanzapine }+ \\
\text { divalproex sodium }(n=1) ; \\
\text { chlorpromazine }+ \text { lorazepam }+ \\
\text { risperidone }+ \text { diphenhydramine }+ \\
\text { haloperidol }(n=1)\end{array}$ \\
\hline
\end{tabular}

Medicines separated with a "+" were those co-suspected but not necessarily given simultaneously, although given close in time.

${ }^{a}$ This report concerned olanzapine-induced rhabdomyolysis and litium-induced electrocardiogram (ECG) changes (Rosebraugh et al. 2001).

${ }^{\mathrm{b}}$ This report concerned hyperthermia and rhabdomyolysis (Strawn et al. 2008).

given; the peak CPKs ranged from 1373 to $77,330 \mathrm{U} / \mathrm{L}$. The cases with the lowest and highest CPK/CK values are presented subsequently. A CK of $858 \mathrm{U} / \mathrm{L}$ was recorded for a 6-year-old boy (Yoshikawa et al. 2000). This boy had stopped haloperidol 2 days prior to the CK test because of a suspected "mild rhabdomyolysis" when his urine myoglobin had been measured to $660 \mathrm{ng} / \mathrm{mL}$. The CPK value of 95,000 was detected by a primary care physician in a 17-yearold male, who complained of lower back pain and dark brown urine. The patient had been treated with a daily dose of risperidone $2.5 \mathrm{mg}$ for an unknown duration, which "recently had been increased to $4 \mathrm{mg}$." The patient was admitted to the hospital, risperidone was stopped, and he was treated with intravenous fluids. Myoglobin in the urine was never detected. He recovered and was discharged with a CPK of $8100 \mathrm{U} / \mathrm{L}$ and was prescribed fluoxetine $30 \mathrm{mg}$ once daily. Further information for this case is given in Table 9 and case 5 .

In eight reports, myoglobin was detected in urine, ranging between 660 and $5930 \mathrm{ng} / \mathrm{mL}$ for the three cases with a known value. Myoglobinemia was recorded for one case and in an additional two cases, myoglobin was recorded without reference to urine or plasma.

\section{Time of drug start to onset of the event}

The time period from start of antipsychotic treatment to onset of symptoms or diagnosis of rhabdomyolysis could be determined in 16 reports in the RM group ranging from 2 days to 1.5 years, and is

Table 7. Number of Cases by Causality Criteria for the 26 Children and Adolescents Reported with Antipsychotic Medicines and Rhabdomyolysis With and Without Neuroleptic Malignant Syndrome (NMS)

\begin{tabular}{lcc}
\hline $\begin{array}{l}\text { WHO causality } \\
\text { criteria }\end{array}$ & $\begin{array}{c}\text { No. reports } \\
\text { with rhabdomyolysis }\end{array}$ & $\begin{array}{c}\text { No. reports with } \\
\text { rhabdomyolysis } \\
\text { co-reported with NMS }\end{array}$ \\
\hline Probable/Likely & 9 & 3 \\
Possible & 9 & 3 \\
Not assessable & 2 & - \\
\hline
\end{tabular}

WHO, World Health Organization. displayed in Table 10, categorized according to records of possible triggering factors at the time of event. In the RM + NMS group, the time to onset ranged from 3 days to 1.5 months $(3,5,5,7,48$ days), although the report with longer latency included very limited case information.

\section{Underlying risk factors for rhabdomyolysis}

Underlying risk factors for rhabdomyolysis in the RM group were recorded for nine patients: strenuous physical activity $(n=3)$, seizure/hysterical seizure $(n=2)$, intramuscular (IM) injection $(n=2)$, diabetic ketoacidosis $(n=1)$, alcohol use $(n=1)$, hyperthermia $(n=1)$, and possible infection $(n=1)$. Two patients had more than one risk factor. The two cases with IM injections presented with unstable psychiatric disorders at the time of diagnosis (Hung et al. 2009; Karakaya et al. 2010).

Underlying risk factors could not be excluded for three additional cases. One patient (severely disabled) had a medical history of seizures, but these were not reported as uncontrolled at the time of rhabdomyolysis. Two patients were taking antiepileptic medicines with an unspecified indication.

\section{Daily doses and route of administration}

Daily doses for the antipsychotic medicines were specified in 20 of the 26 reports. Five of the cases with rhabdomyolysis reported without NMS were recorded with doses in the higher range for their age according to DRUGDEX (DRUGDEX ${ }^{\circledR}$ System); for two of these patients, onset of rhabdomyolysis occurred during dose increase. See Table 9 for case details.

The antipsychotic medicines were administered orally, with the exception of two cases in which IM administration had been used. Both of these cases originated from two published case reports (Hung et al. 2009; Karakaya et al. 2010). In one case, the patient was switched from a 3 week treatment of risperidone $3 \mathrm{mg} /$ day to oral olanzapine $10 \mathrm{mg}$ followed by $5 \mathrm{mg}$ IM injection the next day, after which the patient experienced hypothermia and rhabdomyolysis (Hung et al. 2009). The other case received $10 \mathrm{mg}$ olanzapine IM and then $10 \mathrm{mg}$ as maintenance therapy (Karakaya et al. 2010). The patient only received two doses before being admitted to the hospital for rhabdomyolysis. 
Table 8. Signs and Symptoms Preceding Diagnosis, or Presented on Day of Rhabdomyolysis, Reported Without Neuroleptic Malignant Syndrome, for Children and Adolescents Taking Antipsychotic Medicines

\begin{tabular}{|c|c|c|c|c|c|}
\hline \multirow{2}{*}{$\begin{array}{l}\text { Time prior } \\
\text { to diagnosis }\end{array}$} & \multicolumn{4}{|c|}{ Signs and symptoms } & \multirow[b]{2}{*}{ Other } \\
\hline & Age/Sex & Aches and pain & Movement symptoms & Signs & \\
\hline 1 day & $17 / \mathrm{M}$ & Lower back (DD) & Decreased mobility & Anuria, dark urine (DD) & \\
\hline 2 days & $15 / \mathrm{F}$ & Abdominal (DD) & & Slight CK increase & Vomiting (DD) \\
\hline \multirow{4}{*}{ 4-5 days } & $6 / \mathrm{M}$ & Abdominal, back & & & Seizures \\
\hline & $15 / \mathrm{M}$ & Abdominal & & & Lethargy \\
\hline & $16 / \mathrm{M}$ & $\begin{array}{l}\text { Abdominal, arms, leg } \\
\text { and chest cramps, } \\
\text { muscle aches }\end{array}$ & & Dark urine (DD) & $\begin{array}{l}\text { Diaphoresis, diarrhea, } \\
\text { vomiting } \\
\text { ( } 2 \text { day prior })\end{array}$ \\
\hline & $17 / \mathrm{M}^{\mathrm{a}}$ & Facial myalgia & Restless & Slight CK increase & \\
\hline \multirow[t]{3}{*}{$1-2$ weeks } & $9 / \mathrm{M}$ & Leg pain (DD) & Walking problems (DD) & $\begin{array}{l}\text { Mild fever } \\
\text { (abated before } \\
\text { diagnosis) }\end{array}$ & $\begin{array}{l}\text { Dizziness } \\
\text { (abated before } \\
\text { diagnosis) }\end{array}$ \\
\hline & $15 / \mathrm{M}$ & Muscle & & & Fatigue \\
\hline & $17 / \mathrm{M}^{\mathrm{b}}$ & & & & $\begin{array}{l}\text { Rash, bullous } \\
\text { eruption (DD) }\end{array}$ \\
\hline 3 weeks & $13 / \mathrm{M}^{\mathrm{c}}$ & $\begin{array}{l}\text { Muscle pain, sore throat, } \\
\text { abdominal cramps }\end{array}$ & Walking problems (DD) & & Weakness, diaphoresis \\
\hline $\begin{array}{l}2 \text { months (symptoms } \\
\text { on and off) }\end{array}$ & $6 / M^{\mathrm{d}}$ & & & Dark urine & \\
\hline \multirow[t]{6}{*}{ Day of diagnosis } & $12 / \mathrm{M}$ & Headache & & Dark urine & \\
\hline & $13 / \mathrm{M}^{\mathrm{e}}$ & Muscle tenderness & $\begin{array}{l}\text { Restless, stereotypical } \\
\text { movements, } \\
\text { head banging }\end{array}$ & & \\
\hline & $14 / \mathrm{F}$ & Abdominal & & & \\
\hline & $14 / \mathrm{F}^{\mathrm{f}}$ & & & $\begin{array}{l}\text { High fever, hypotensive, } \\
\text { sinus tachycardia }\end{array}$ & Unresponsive \\
\hline & $17 / \mathrm{F}$ & & & Atrial fibrillation & \\
\hline & $17 / \mathrm{M}^{\mathrm{g}}$ & & & Hypothermic, hypotensive & Drowsy, drooling \\
\hline
\end{tabular}

Each row represents the events for the 17 cases with this information specified.

${ }^{\text {a}}$ Holtmann et al. 2003.

${ }^{b}$ Reported with rhabdomyolsis and/or bullous eruption (Case 1 in Table 9).

${ }^{\mathrm{c}}$ Rosebraugh et al. 2001.

${ }^{\mathrm{d}}$ Yoshikawa et al. 2000.

e Karakaya et al. 2010.

f Strawn et al. 2008.

${ }^{\mathrm{g}}$ Hung et al. 2009.

$\mathrm{CK}$, creatine kinase; DD, day of diagnos.

\section{Concomitant drugs}

Apart from the co-suspected drugs (Table 6), commonly reported concomitant drugs were antiepileptic medicines $(n=5$ for RM group; $n=2$ for RM + NMS group) and antidepressants ( $n=3$ for RM group; $n=1$ for RM+NMS group).

In the RM group, the number of reported drugs (irrespective of whether they were reported as suspected or concomitant) ranged from one to six drugs with a median of two recorded drugs per report. In the RM+NMS group, the number of reported drugs ranged from 1 to 11 drugs with a median of 4.5 drugs.

\section{Withdrawal of treatment, outcome, and seriousness of the event}

The antipsychotic medicine was stated to have been withdrawn in all reports. Twenty-one of the 26 patients recovered. Of the 20 patients in the RM group, 16 recovered/were recovering on the day of report and 5 of the 6 cases recovered in the RM+NMS group. Four reports included limited follow-up information, of which one report concerned a 13-year-old male with the following record "the patient developed rhabdomyolysis and had to have one of his legs amputated." In another report for a 15-year-old male with pancre- atitis, diabetic ketoacidosis, and rhabdomyolysis, it was stated that the patient recovered from the acute event but that the "patient may have permanent damage". In two reports, the 17-year-old males with renal complications had not recovered on the day of report. An 8-year-old female co-reported with NMS died of multi-organ failure. This report originated from a poison control center and was accounted for in the 2003 annual report of the American Association of Poison Control Centers Toxic Exposure Surveillance System (Watson et al. 2004). Rhabdomyolysis resulted in renal problems in three of the patients in the RM group, detailed in Table 9.

In all but two cases among the 26 reports, the patients were hospitalized or their hospitalization was prolonged. In two VigiBase ICSRs, it was not specified whether the patient had been hospitalized.

\section{Critical Review of Individual Case Safety Reports in VigiBase}

Eighteen original VigiBase ICSRs files of rhabdomyolysis with and without NMS were evaluated for clinical usefulness (published case reports and the poison control abstract were excluded) with results displayed in Table 11 . 


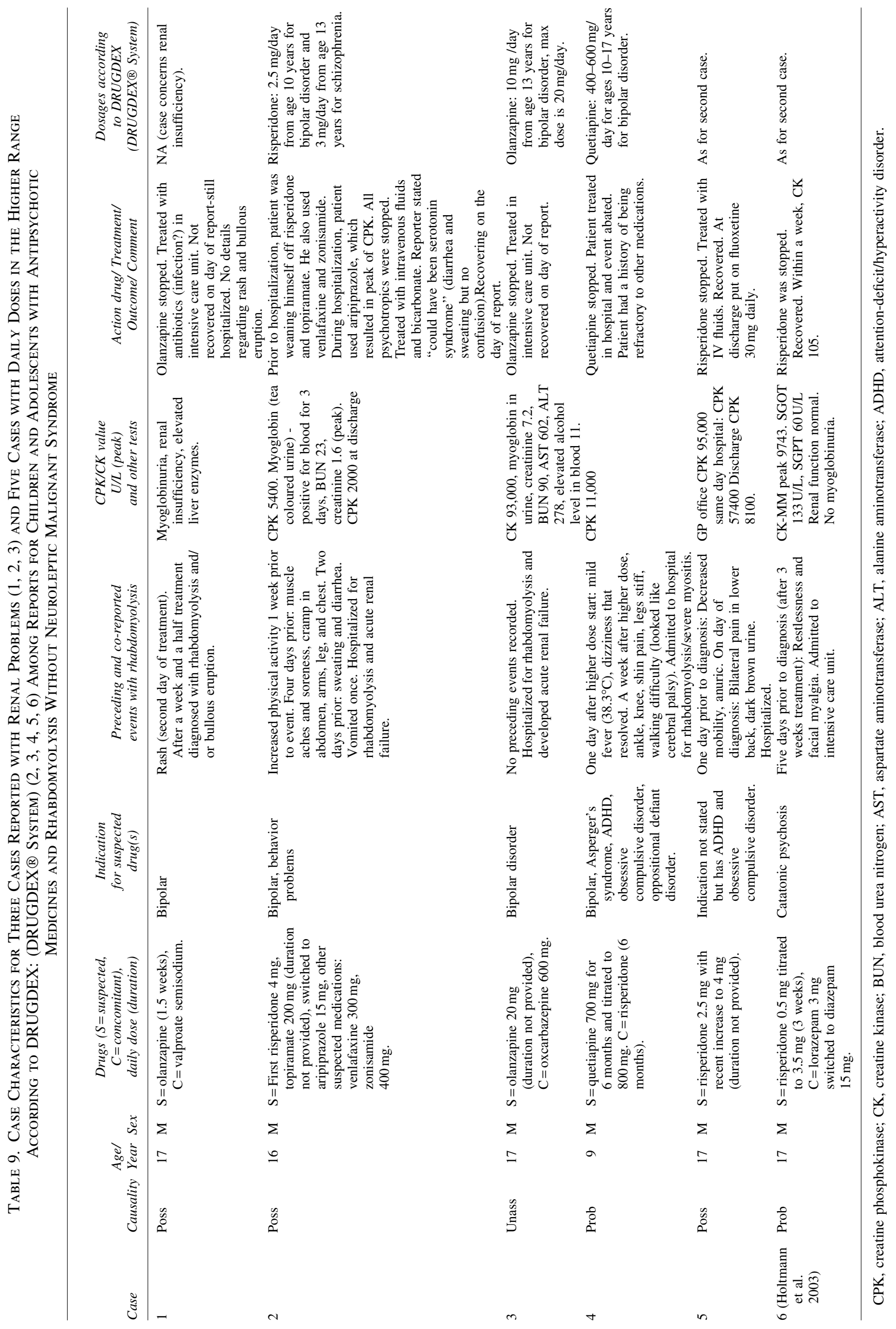


Table 10. Time to Onset for Rhabdomyolysis RePORTED Without Neuroleptic Malignant Syndrome After Start of ANTIPSyCHOtic MEDiCINES FOR ChILdREN and Adolescents, Where Time Latency Could Be Determined

\begin{tabular}{llc}
\hline $\begin{array}{l}\text { Time } \\
\text { to } \text { onset }\end{array}$ & $\begin{array}{c}\text { Possible triggering factors } \\
\text { for rhabdomyolysis recorded }\end{array}$ & $\begin{array}{c}\text { No. } \\
\text { reports }\end{array}$ \\
\hline 2 days & $\begin{array}{l}\text { Intramuscular injections and } \\
\text { unstable psychiatric disease }\end{array}$ & 2 \\
$3-7$ days & $\begin{array}{l}\text { Other antipsychotic added } \\
\text { Dose increase (lower dose } \\
\text { used 6 months) }\end{array}$ & 2 \\
& $\begin{array}{l}\text { None recorded } \\
\text { Concomitant underlying risk } \\
\text { factors }\end{array}$ & 1 \\
& $\begin{array}{l}\text { None recorded } \\
\text { Concomitant underlying risk } \\
\text { 1-2 months }\end{array}$ & factors \\
& $\begin{array}{l}\text { None recorded } \\
\text { None recorded }\end{array}$ & 1 \\
1.5 years & & 3 \\
& & 1 \\
& & 1
\end{tabular}

${ }^{\text {a }}$ Possible infection.

${ }^{\mathrm{b}}$ Hysterical seizures and intensive sit-ups; strenuous activity and hyperthermia; diabetic ketoacidosis; seizure.

\section{Discussion}

Clinical features and possible risk factors of rhabdomyolysis in children and adolescents receiving antipsychotics

In this study, 20 reports of children and adolescents with rhabdomyolysis in the absence of NMS, who had been treated with antipsychotic medicines, are described. Abdominal pain or cramps and muscle pains were common symptoms recorded during the week preceding the diagnosis of rhabdomyolysis. Four cases had abdominal pain prior to the rhabdomyolysis diagnosis and two additional cases presented with abdominal pain at the time of diagnosis (of which one had recently completed a set of extensive situps). Abdominal pain has not been described as a typical clinical symptom of rhabdomyolysis. However, in a chart review of children and adolescents with rhabdomyolysis from any cause, $12 \%$ of the 191 cases presented with abdominal tenderness (Mannix et al. 2006). Abdominal pain could have been an innocent bystander in our case series because of its common occurrence in youth (Gieteling et al. 2011). However, rhabdomyolysis is a serious ADR, and unexpected abdominal pain should still serve as an alert for further investigation to eliminate the possibility of emerging rhabdomyolysis in a child or adolescent treated with antipsychotics.

Rhabdomyolysis was reported more frequently with olanzapine relative to reports on all children and adolescents with antipsychotic medicines in VigiBase. The higher reporting for olanzapine in our case series could be the result of reporting bias from published case reports on olanzapine (Rosebraugh et al. 2001; Strawn et al. 2008; Hung et al. 2009; Karakaya et al. 2010), although three of these case reports were published in or after 2008, whereas all but one of the VigiBase ICSRs on olanzapine in our case series were reported before that year. The reason for the higher reporting for olanzapine could also be that it is more prone to induce rhabdomyolysis than are other antipsychotics.

Ribeyron et al. reviewed 21 published and reported cases on olanzapine and rhabdomyolysis from the French pharmacovigilance database, mainly in adults (Ribeyron et al. 2009). Two cases in the French study overlapped with two cases described here, one published case report (Rosebraugh et al. 2001) and one VigiBase case. The overall results in the French study and in our study corresponded, although the upper range of CPK was higher for the subjects in our study. A possible explanation for the overall corresponding pattern between youth and adult reports could be that

Table 11. Categorization of Selected Clinical Information on 18 VigiBase Individual Case Safety Reports Using Original Files, (Published Case Reports Excluded) for Children and Adolescents with Antipsychotic Medicines and Rhabdomyolysis With and Without Neuroleptic Malignant Syndrome

\begin{tabular}{|c|c|c|c|}
\hline Report information category & No. reports & Structured (searchable) data & Free text \\
\hline $\begin{array}{l}\text { Circumstances preceding the } \\
\text { reaction (where information } \\
\text { was available) }\end{array}$ & 8 & $\begin{array}{l}\text { Listed as reaction: } n=5 \\
\text { Some of the reactions are listed: } n=1 \\
\text { None of the reactions are listed: } n=2 \\
\text { The listed preceding reactions had the same } \\
\text { onset date as rhabdomyolysis. }\end{array}$ & $n=8$ \\
\hline $\begin{array}{l}\text { Underlying risk factors for } \\
\text { rhabdomyolysis(excluding } \\
4 \text { NMS cases) }\end{array}$ & 6 & Listed as an ADR, convulsion: $n=1$ & $n=6$ \\
\hline $\begin{array}{l}\text { Physical examination } \\
\text { or laboratory tests }\end{array}$ & $\begin{array}{l}16 \text { of which } \\
13 \text { included } \\
\text { values }\end{array}$ & $\begin{array}{l}\text { CPK increase: } n=4 \\
\text { Other laboratory abnormalities: } n=4 \\
\text { Myoglobinuria: } n=0 \\
\text { Pyrexia: } n=2\end{array}$ & $\begin{array}{l}\text { CPK/CK: } n=14 \text { (with values: } n=12 \text { ) } \\
\text { Other laboratory abnormalities: } \\
n=9 \text { (with values: } n=5 \text { ) } \\
\text { Myoglobinuria: } n=5 \\
\text { Myoglobin in urine or serum: } n=1 \\
\text { (with value) } \\
\text { Myoglobinemia: } n=1 \text { (with value) } \\
\text { Temperature: } n=5 \text { (one stated "no } \\
\text { fever") }\end{array}$ \\
\hline Reaction time-to-onset & 13 & $n=9$ & $n=4($ only free text $)$ \\
\hline $\begin{array}{l}\text { Treatment of the reaction } \\
\text { (other than hospitalization } \\
\text { or stopping the drug) }\end{array}$ & 5 & - & $n=5$ \\
\hline
\end{tabular}

CPK, creatine phosphokinase; CK, creatine kinase, NMS, neuroleptic malignant syndrome; ADR, adverse drug reaction. 
the median age was 14.5 in our study, and therefore near the adult group in age.

Rhabdomyolysis in association with antipsychotic use is recorded as occurring only rarely (Summary of Product Characteristics [U.K.] 2012). The rarity and unspecific early symptoms of rhabdomyolysis might contribute to the difficulty of recognizing this as a drug-induced reaction. In one case, a boy had troubles with weakness and walking problems over 4 weeks, which was interpreted by resident care staff as disobedience, before being recognised as ADRs (Rosebraugh et al. 2001). In another case, a mother noticed her son passing tea-coloured urine on and off for 2 months before she consulted healthcare professionals (Yoshikawa et al. 2000). The time period between the antipsychotic start and onset of rhabdomyolysis could range up to 2 months, as seen in our study, possibly reducing the likelihood of suspecting the antipsychotic as the causative agent. Hence, rhabdomyolysis might not only be difficult to recognize but also less likely to be reported as an ADR. On the other hand, NMS occurred within a week of the antipsychotic start, as indicated by four of the six cases of rhabdomyolysis co-reported with NMS in our case series.

In several of the studied cases, the onset of rhabdomyolysis occurred in connection with a dose increase or when antipsychotic medicines were switched or added to the patient's drug regimen. Exposure to known risk factors for rhabdomyolysis, such as intramuscular injection, alcohol use, and strenuous physical activity, could have played a role in developing rhabdomyolysis in some of our cases. Concomitant conditions such as seizures or an uncontrolled psychiatric disease, particularly with manic symptoms, could also be reasons for developing or precipitating rhabdomyolysis. Many of the cases in our review could have been influenced by such risk factors when considering underlying disease. Nevertheless, the majority of patients improved when the drug was withdrawn, suggesting a causal relationship between the antipsychotic medicine and rhabdomyolysis. The use of antipsychotic medicines in combination with these factors could have triggered the development of rhabdomyolysis in our cases, as the syndrome often presents itself with more than one etiological factor (Melli et al. 2005).

\section{Strengths and limitations of the study}

This study gives a collected and detailed picture of how children and adolescents can present with antipsychotic-induced rhabdomyolysis. The information aims to increase awareness of the features of this rare ADR in clinical practice, and thereby enhance the chances of capturing the early symptoms of rhabdomyolysis in order to prevent the development of serious consequences for this vulnerable patient group. We chose to restrict our search to reports with a high degree of likelihood that the report was specific for rhabdomyolysis. Because of this approach, there were a limited number of reports in this case series; therefore, the findings in this study cannot be used quantitatively. VigiBase does not include denominator information for the reported drugs, and the reporting system suffers from underreporting (Hazell et al. 2006); hence, we cannot give the prevalence of rhabdomyolysis in association with antipsychotic medicines for children and adolescents. Other limitations of the reporting system are that recommendations and requirements for reporting ICSRs vary among countries, and also, that the amount of information given, as well as the likelihood that a medicine caused the ADR, may vary from case to case. On the other hand, in a recent published cohort study of 2767 child and adolescent patients on antipsychotic drugs, no case of rhabdomyolysis was identified (Rani et al. 2011), as the prevalence of antipsychotic drug use in children is very low and a cohort study is often too small to capture this rare ADR.

In this case series analysis, the ICSRs were found to contribute with useful clinical information in addition to the published cases. The availability of case narratives was crucial to capture information describing which events preceded rhabdomyolysis and when they occurred, underlying risk factors, laboratory values, and treatment of the reaction. However, the information recorded on the reports regarding underlying risk factors and treatment of the reaction was sparse despite access to a narrative. More work and education are needed not only to increase reporting but also to enhance the amount and quality of case details on ICSRs.

\section{Conclusion}

Monitoring of children and adolescents needs to be intensified during dose increases, when a new, added, or switched antipsychotic medicine is introduced to their drug regimen and during exposure to known risk factors for rhabdomyolysis. During antipsychotic treatment, it is important to follow up unexpected signs and symptoms not usually present in the individual patient. The development of seemingly nonserious events such as abdominal pain, muscle pain, weakness, and dark urine should be investigated during antipsychotic use, as they might be precursory events to rhabdomyolysis that eventually could develop into acute renal failure.

\section{Disclosures}

N. Iessa, N. Almandil, L. Wilton, S. Curran, and I.R. Edwards have no conflicts of interest relevant to this article. K. Star has a limited number of stocks in AstraZeneca, the manufacturer of quetiapine. I.C.K. Wong has received research funding and honoraria from various pharmaceutical companies including JanssenCilag and Bristol-Myers Squibb (manufacturers of antipsychotic medicines). I.C.K. Wong is currently receiving funding from the European Union Commission to investigate the safety of risperidone in children.

\section{Acknowledgments}

The authors are indebted to the National Pharmacovigilance Centres that contributed with data. The opinions and conclusions in this study are not necessarily those of the various centres or of the WHO. The authors also give special thanks to Johan Hopstadius and Kristina Juhlin at the Uppsala Monitoring Centre, for the computational support for this study.

\section{References}

Almandil NB, Liu Y, Murray LM, Besag FMC, Aitchison KJ, Wong ICK: Weight gain and other metabolic adverse effects associated with atypical antipsychotic treatment of children and adolescents: A systematic review and meta-analysis. Paediatr Drugs (in press).

Almandil NB, Wong IC: Review on the current use of antipsychotic drugs in children and adolescents. Arch Dis Child Educ Pract Ed 96:192-196, 2011.

Bate A, Lindquist M, Edwards IR, Olsson S, Orre R, Lansner A, De Freitas RM: A Bayesian neural network method for adverse drug reaction signal generation. Eur J Clin Pharmacol 54:315-321, 1998.

Bégaud B, Evreux JC, Jouglard J, Lagier G: Imputation of the unexpected or toxic effects of drugs. Actualization of the method used in France [in French]. Thérapie 40:111-118, 1985.

Cheng-Shannon J, McGough JJ, Pataki C, McCracken JT: Secondgeneration antipsychotic medications in children and adolescents. J Child Adolesc Psychopharmacol 14:372-394, 2004. 
Correll CU, Carlson HE: Endocrine and metabolic adverse effects of psychotropic medications in children and adolescents. J Am Acad Child Adolesc Psychiatry 45:771-791, 2006.

DRUGDEX ${ }^{\circledR}$ System. Micromedex ${ }^{\circledR} 2.0$. Available at www.thomsonhc.com/micromedex/librarian Accessed November 8, 2012.

Elsayed EF, Reilly RF: Rhabdomyolysis: A review, with emphasis on the pediatric population. Pediatr Nephrol 25:7-18, 2010.

Gabow PA, Kaehny WD, Kelleher SP: The spectrum of rhabdomyolysis. Medicine (Baltimore) 61:141-152, 1982.

Gieteling MJ, Lisman-van Leeuwen Y, van der Wouden JC, Schellevis FG, Berger MY: Childhood nonspecific abdominal pain in family practice: Incidence, associated factors, and management. Ann Fam Med 9:337-343, 2011.

Hanft A, Eggleston CF, Bourgeois JA: Neuroleptic malignant syndrome in an adolescent after brief exposure to olanzapine. J Child Adolesc Psychopharmacol 14:481-487, 2004.

Hazell L, Shakir SA: Under-reporting of adverse drug reactions: A systematic review. Drug Saf 29:385-396, 2006.

Holtmann M, Meyer AE, Pitzer M, Schmidt MH: Risperidoneinduced marked elevation of serum creatine kinase in adolescence. A case report. Pharmacopsychiatry 36:317-318, 2003.

Hung CF, Huang TY, Lin PY: Hypothermia and rhabdomyolysis following olanzapine injection in an adolescent with schizophreniform disorder. Gen Hosp Psychiatry 31:376-378, 2009.

Jerrell JM, McIntyre RS: Adverse events in children and adolescents treated with antipsychotic medications. Hum Psychopharmacol 23:283-290, 2008.

Jones JK: Adverse drug reactions in the community health setting: approaches to recognizing, counseling, and reporting. Fam Community Health 5:58-67, 1982.

Karakaya P, Yis U, Kurul SH, Turkmen MA: Rhabdomyolysis associated with olanzapine treatment in a child with autism. Pediatr Emerg Care 26:41-42, 2010.

Kelly WN, Arellano FM, Barnes J, Bergman U, Edwards RI, Fernandez AM, Freedman SB, Goldsmith DI, Huang KA, Jones JK, McLeay R, Moore N, Stather RH, Trenque T, Troutman WG, van Puijenbroek E, Williams F, Wise RP: Guidelines for submitting adverse event reports for publication. Drug Saf 30:367373, 2007.

Lindquist M: Vigibase, the WHO Global ICSR Database System: Basic Facts. Drug Inf J 42:409-419, 2008.

Maintenance and Support Service Organization (MSSO). (2010). MedDRA - the Medical Dictionary for Regulatory Activities. Available at www.meddramsso.com Accessed November 19, 2010.

Mannix R, Tan ML, Wright R, Baskin M: Acute pediatric rhabdomyolysis: Causes and rates of renal failure. Pediatrics 118:21192125, 2006.

Melli G, Chaudhry V, Cornblath DR: Rhabdomyolysis: an evaluation of 475 hospitalized patients. Medicine (Baltimore) 84:377-385, 2005.

Naranjo CA, Busto U, Sellers EM, Sandor P, Ruiz I, Roberts EA, Janecek E, Domecq C, Greenblatt DJ: A method for estimating the probability of adverse drug reactions. Clin Pharmacol Ther 30:239 245, 1981.

Norén GN, Hopstadius J, Bate A: Shrinkage observed-to-expected ratios for robust and transparent large-scale pattern discovery. Stat Methods Med Res 2011 [Epub ahead of print].

Norén GN, Orre R, Bate A, Edwards IR: Duplicate detection in adverse drug reaction surveillance. Data Min Knowl Discov 14:305328, 2007.

Olfson M, Blanco C, Liu L, Moreno C, Laje G: National trends in the outpatient treatment of children and adolescents with antipsychotic drugs. Arch Gen Psychiatry 63:679-685, 2006.
Pathak P, West D, Martin BC, Helm ME, Henderson C: Evidencebased use of second-generation antipsychotics in a state Medicaid pediatric population, 2001-2005. Psychiatr Serv 61:123-129, 2010.

Rani FA, Byrne P, Cranswick N, Murray ML, Wong IC: Mortality in children and adolescents prescribed antipsychotic medication: A retrospective cohort study using the UK general practice research database. Drug Saf 34:773-781, 2011.

Rani FA, Byrne PJ, Murray ML, Carter P, Wong IC: Paediatric atypical antipsychotic monitoring safety (PAMS) study: pilot study in children and adolescents in secondary- and tertiary-care settings. Drug Saf 32:325-333, 2009.

Rani FA, Murray ML, Byrne PJ, Wong IC: Epidemiologic features of antipsychotic prescribing to children and adolescents in primary care in the United Kingdom. Pediatrics 121:1002-1009, 2008.

Ribeyron S, Guy C, Koenig M, Cathebras P: Olanzapine induced rhabdomyolysis and serum creatine kinase increase [in French]. Rev Méd Interne 30:477-485, 2009.

Rosebraugh CJ, Flockhart DA, Yasuda SU, Woosley RL: Olanzapineinduced rhabdomyolysis. Ann Pharmacother 35:1020-1023, 2001.

Sikich L, Frazier JA, McClellan J, Findling RL, Vitiello B, Ritz L, Ambler D, Puglia M, Maloney AE, Michael E, De Jong S, Slifka K, Noyes N, Hlastala S, Pierson L, McNamara NK, Delporto-Bedoya D, Anderson R, Hamer RM, Lieberman JA: Double-blind comparison of first- and second-generation antipsychotics in early-onset schizophrenia and schizo-affective disorder: Findings from the treatment of early-onset schizophrenia spectrum disorders (TEOSS) study. Am J Psychiatry 165:1420-1431, 2008.

Sikich L, Hamer RM, Bashford RA, Sheitman BB, Lieberman JA: A pilot study of risperidone, olanzapine, and haloperidol in psychotic youth: A double-blind, randomized, 8-week trial. Neuropsychopharmacology 29:133-145, 2004.

Strawn JR, Adler CM, Strakowski SM, DelBello MP: Hyperthermia and rhabdomyolysis in an adolescent treated with topiramate and olanzapine. J Child Adolesc Psychopharmacol 18:116-118, 2008.

Summary of Product Characteristics (UK). (2012). Olanzapine. Available at www.medicines.org.uk/EMC/searchresults.aspx?term = olanzapine\&searchtype = QuickSearch Accessed July 5, 2012.

Vandenbroucke JP: Case reports in an evidence-based world. J R Soc Med 92:159-163, 1999.

Vandenbroucke JP: In defense of case reports and case series. Ann Intern Med 134:330-334, 2001.

Watson WA, Litovitz TL, Klein-Schwartz W, Rodgers GC, Jr., Youniss J, Reid N, Rouse WG, Rembert RS, Borys D: 2003 annual report of the American Association of Poison Control Centers Toxic Exposure Surveillance System. Am J Emerg Med 22:335-404, 2004.

WHO Collaborating Centre for Drug Statistics Methodology. ATC classification index with DDDs, Oslo, 2008

$\mathrm{Wu} \mathrm{CT}$, Huang JL, Lin JJ, Hsia SH: Factors associated with nontraumatic rhabdomyolysis and acute renal failure of children in Taiwan population. Pediatr Emerg Care 25:657-660, 2009.

Yoshikawa H, Watanabe T, Abe T, Oda Y, Ozawa K: Haloperidolinduced rhabdomyolysis without neuroleptic malignant syndrome in a handicapped child. Brain Dev 22:256-258, 2000.

Address correspondence to: Kristina Star, B.SC

Uppsala Monitoring Centre WHO Collaborating Centre for International Drug Monitoring Uppsala Sweden

E-mail: kristina.star@who-umc.org 
Appendix A

World Health Organization-Uppsala Monitoring Centre Causality Categories

\begin{tabular}{|c|c|}
\hline Causality term & Assessment criteria \\
\hline Certain & $\begin{array}{l}\text { - Event or laboratory test abnormality, with plausible time relationship to drug intake } \\
\text { - Cannot be explained by disease or other drugs } \\
\text { - Response to withdrawal plausible (pharmacologically, pathologically) } \\
\text { - Event definitive pharmacologically or phenomenologically (i.e., an objective and specific } \\
\text { medical disorder or a recognized pharmacological phenomenon) } \\
\text { - Rechallenge satisfactory, if necessary }\end{array}$ \\
\hline Probable/Likely & $\begin{array}{l}\text { - Event of laboratory test abnormality, with reasonable time relationship to drug intake } \\
\text { - Unlikely to be attributed to disease or other drugs } \\
\text { - Response to withdrawal clinically reasonable } \\
\text { - Rechallenge not required }\end{array}$ \\
\hline Possible & $\begin{array}{l}\text { - Event or laboratory test abnormality, with reasonable time relationship to drug intake } \\
\text { - Could also be explained by disease or other drugs } \\
\text { - Information on drug withdrawal may be lacking or unclear }\end{array}$ \\
\hline Unlikely & $\begin{array}{l}\text { - Event or laboratory test abnormality, with a time to drug intake that makes a relationship } \\
\text { improbable (but not impossible) } \\
\text { - Disease or other drugs provide plausible explanations }\end{array}$ \\
\hline Conditional / Unclassified & $\begin{array}{l}\text { - Event or laboratory test abnormality } \\
\text { - More data for proper assessment needed, or } \\
\text { - Additional data under examination }\end{array}$ \\
\hline Unassessable / Unclassifiable & $\begin{array}{l}\text { - Report suggesting an adverse reaction } \\
\text { - Cannot be judged because information is insufficient or contradictory } \\
\text { - Data cannot be supplemented or verified }\end{array}$ \\
\hline
\end{tabular}


This article has been cited by:

1. Charles Schulz, Robert J Haight. 2013. Safety of olanzapine use in adolescents. Expert Opinion on Drug Safety 12:5, 777-782. [CrossRef]

2. Macey L. Murray, Yingfen Hsia, Karen Glaser, Emily Simonoff, Declan G. M. Murphy, Philip J. Asherson, Hanna Eklund, Ian C. K. Wong. 2013. Pharmacological treatments prescribed to people with autism spectrum disorder (ASD) in primary health care. Psychopharmacology . [CrossRef]

3. 2013. Re: J Child Adolesc Psychopharm 22:440-451, 2012. Journal of Child and Adolescent Psychopharmacology 23:2, 142-142. [Citation] [Full Text HTML] [Full Text PDF] [Full Text PDF with Links] 